He had not seen Mr. Burstow's clutch mentioned by Mr. Boys.

In speaking of the loss of power due to perpetually bending steel driving bands he did not refer to the very thin bands of the Otto, but to. driving bands with holes to fit over pins some four or five times as thick.

The Chairman considered it an open question whether the path of a bicyclist were really wavy as theory seemed to show. He had often watched a bicyclist and it was almost impossible to believe that he did not travel in a straight path. He thought this question worthy of more attention. $\mathrm{He}$ had heard it asserted that no advantage could be gained by the use of artificial cycles over natural legs, but it must be remembered that legs were implements fitted for other purposes besides running, such as jumping and climbing. Again, no one supposed that a horse could carry on his back such a load as he could easily draw in a carriage on a road; here the extra weight of the carriage corresponded to the addition of the bicycle.

As in many other industries, bicycle and tricycle construction depended to a large extent for its success upon the perfection of many details of construction; as instances of important details he referred to rubber, steel wire, steel stampings, and driving-gear. Having made some remarks on the necessity of good roads he expressed the opinion that in time cycle ways might be laid down with advantage.

It was a mistake to suppose that cycling was only suitable for the young and active; people of all ages and conditions might enjoy the benefits of the wheel. The advantage of a sound machine to a labouring man, or of a hand-driven machine to a lame man, was inestimable, while invalids could even enjoy a run to the seaside in a Coventry-chair without the annoyance of cabs, railway stations, and trains. Having proposed a hearty vote of thanks to Mr. Phillips for his paper, he brought the proceedings to a close.

\section{ALFRED TRIBE}

$\mathrm{O}^{\mathrm{N}}$ November 26 died, after a very short illness, Mr. Alfred Tribe. He was born in London forty-six years ago in humble circumstances, and his first acquaintance with science seems to have been obtained as a boy at the Royal College of Chemistry. While waiting upon the students there he acquired whatever knowledge he could, and repeated in a back kitchen at home many of the experiments he had seen them perform. Prof. Hofmann, pleased with his desire for knowledge, gave him every encouragement and assistance in his power. At the age of sixteen he entered into the service of Dr. Medlock, then of Dr. Forbes Watson, and afterwards he assisted Prof. Williamson, of University College. He then went to Dr. Bernays, who after some time induced him to spend a year at Heidelberg under Prof. Bunsen, and kept his place at St. Thomas's Hospital open for him while he was away. On his return he continued to act as laboratory assistant and Demonstrator of Chemistry.

Twenty years ago he became my private assistant, and remained head of my laboratory till his death. During the same time he held the Lectureship on Metallurgy to the Medical School of the National Dental Hospital, and since 1874 he has been Lecturer on Chemistry and Director of Practical Chemistry in Dulwich College.

He became successively a Fellow of the Chemical Society, of the Institute of Chemistry, and of the Society of Chemical Industry.

Mr. Tribe was pre-eminently a scientific investigator He loved patient and original research, and all his work was most carefully and honestly done. He published a large number of papers, some in his own name, and others in conjunction with myself. His first paper was on
Sulphide of Ammonium, his second on the Expansion of Bismuth at the Freezing-point. His more important inquiries were connected with the occlusion of hydrogen by copper and the rarer metals, and especially a series of experiments on the distribution of the electricity in an electrolyte traversed by a current. The curious and suggestive results of this investigation appear in abstract in the Proceedings of the Royal Society for January and June, I88I, but they are most fully expounded, with coloured illustrations, in the second edition of Mr. J. E. H. Gordon's Treatise on Electricity and Magnetism."

His most important research in conjunction with myself is contained in a series of papers on the CopperZinc Couple, published principally in the Fournal of the Chemical Society. He was the first to observe the greatly enhanced chemical power of zinc when covered with spongy copper. Whatever value there was in this extended research was due to his original suggestions, as much as to his careful manipulation. The same credit is due to him with regard to the series of papers on the aluminium-iodine reaction, the last of which was read only the night before he was taken ill. His discovery of these two new methods of acting upon chemical compounds was productive of many new substances, including the aluminium alcohols.

In addition to these chemical inquiries, we worked together on some electrical matters-describing an airbattery, that is, one in which the oxygen of the air took part; some experiments on thermal electrolysis; and, more particularly, the chemistry of the secondary batteries of Planté and Faure. The results of this investigation were first made known through the pages of NATURE, and were afterwards collected together in a separate treatise.

As a teacher of science, Mr. Tribe was very successful. He had the art of communicating his own enthusiasm to his laboratory students, and many of them have distinguished themselves since at the Universities or elsewhere. Only the week before his death he had the satisfaction of knowing that his favourite science was to receive a more worthy share of attention in the Dulwich College.

At these pursuits Mr. Tribe worked earnestly and continuously, being little known beyond his laboratories and his home. His widow, and four surviving children, together with a small circle of intimate friends, will however long remember the thorough uprightness of his character, and the self-denying purpose of his life.

\section{J. H. Gladstone}

\section{FORDAN'S PHOTOGRAPHIC SUNSHINE RECORDER}

U to the present time the only instruments in general use for registering the duration of sunshine are modifications of the original apparatus invented by the late Mr. J. F. Campbell, of Islay, in 1853, the essential part of which consists of a clear glass globe capable of condensing the solar rays sufficiently to burn a trace on a card placed within its focal range. New forms of instruments have, however, been lately devised, and in the International Inventions Exhibition there were exhibited two Sunshine-recorders differing entirely from those hitherto used, the results being obtained by means of photography. Prof. McLeod's instrument was described in NATURE (vol. xxxi. p. 319), and we now give particulars of Mr. Jordan's photographic Sunshine-recorder. This instrument is of very simple construction. The working part consists of a cylindrical box or dark chamber $2 \frac{1}{2}$ inches diameter and $3 \frac{1}{2}$ inches long, mounted on a suitable stand having the means of adjustment to suit the latitude of the station where used. This cylinder is pierced with two small rectangular apertures or knifeedged slits, and, being placed in a position facing south, 